\title{
SPRAY STRETCH TECHNIQUE VERSUS PROGRESSIVE PRESSURE RELEASE ON TRATMENT OF MYOFACIAL PAIN TRIGGER POINT: RANDOMIZED CONTROLLED TRIAL
}

\section{Doaa Ibrahim Amin}

Basic Science Department, Faculty of Physical Therapy, Cairo University, Egypt

\section{ABSTRACT}

Background: Myofascial trigger points are extremely common and become a distressing part of nearly everyone's life at one time and another. The pain of myofascial trigger points can devastate the quality of life.

Materials and Methods: Thirty participants with acute myofascial trigger points of upper fibre of trapezius were assigned randomly to one of the two study groups: Group (A) 14 participants received spray and stretch technique .Group (B) 16 participants received progressive pressure release technique. Pressure algometer and neck disability index were measured pre and post the intervention period.

Results: Unpaired t- test assesses pain threshold and individuals daily activities pain between the two groups for post intervention values. There was significant difference between Group A and Group B in the post values of pain threshold and individuals daily activities pain. There was a significant increase in pain threshold in group (B) than Group A, and there was significant decrease in individual's activities pain in group A than group B.

Conclusion: Our results show that spray and stretch technique applied after progressive pressure release technique decreases pain should be follow by an increase in the functional activities.

KEY WORDS: Spray and Stretch technique, Progressive pressure release technique, Active myofascial trigger points, Pressure algometer, Neck disability index.

Address for correspondence: Doaa I. Amin, PhD, PT, Lecturer of Physical Therapy Basic Science Department, Faculty of Physical Therapy, Cairo University, Egypt. Cellular Phone: +201004819993 E-Mail: mostafahosam804@gmail.com

\begin{tabular}{|c|c|c|}
\hline \multicolumn{3}{|c|}{ Access this Article online } \\
\hline $\begin{array}{l}\text { Quick Response code } \\
\text { (15p }\end{array}$ & $\begin{array}{r}\text { International Journa } \\
\text { ISSN } \\
\text { www.ijr }\end{array}$ & $\begin{array}{l}\text { Physiotherapy and Research } \\
\text { 21- } 1822 \\
\text { org/ijpr.html }\end{array}$ \\
\hline DOI: $10.16965 /$ ijpr.2017.151 & $\begin{array}{l}\text { Received: 01-04-2017 } \\
\text { Peer Review: 11-04-2017 } \\
\text { Revised: None }\end{array}$ & $\begin{array}{l}\text { Accepted: 24-04-2017 } \\
\text { Published (O): 11-06-2017 } \\
\text { Published (P): 11-06-2017 }\end{array}$ \\
\hline
\end{tabular}

\section{INTRODUCTION}

Skeletal muscle is the biggest organ of human body, which represents $50-55 \%$ of the body weight [1]. Myofascial trigger point (MTrp) is an irritating spot, ordinarily with tangible knobs in tight band of the muscle that is agonizing on pressure and can produce referred pain and tenderness [2]. People with age ranged from (20-45) years are most likely to experience the adverse effects of active trigger point [3] its prevalence in women is more than in men [4].

Sixty one\% of patients went to by physiotherapist with musculoskeletal agony experience the adverse effects of myofascial pain disorder [5]. Active MTrp are related with many pain conditions, for example, shoulder discomfort, mechanical neck pain, pressure and migraine. There are other features associated with MTrp rather than pain for instance modified muscle initiation, muscle strain, muscle shorting and limited motion [6]. Trapezius is found to be the muscle most often affected by MTrp [6] the point of physiotherapy treatment in administration of MTrp is to diminish the pain and reestablish typical capacity by deactivating the MTrp [7].

Newly activated and moderate irritable trigger 
point can be treated by stretching [8]. In treating trigger focuses Simons et al (1999) advcates spray and stretch technique as a non-intrusive strategy to deactivate active trigger point, musculoskeletal disorders and increase movement of different joints [9].

Progressive pressure release method is a manual strategy utilizing the thumbs, knuckles or four fingers of one or both hands enduring weight was connected moving internally toward the inside. When tissue separation was felt, we halted and held up until resistance scattered [9].

Barnes(1999), Manheim(2001) and Baldry and Thompson (2005) said that myofascial trigger point pressure release concentrates straightforwardly on the limited myofascial components with in which the myofascial trigger pointed are found $[10,11,12]$.

There are lots of studies being performed to treat myofascial pain trigger point of upper fiber of trapezius with result measure of pain qualities of myofascial point disorder, for example, intensity of pain and pressure threshold $[6,13,14,15]$.

Few reviews measure the result of pain pressure threshold and disability of movement. Up till now there are no reviews to think about spray and stretch technique versus progressive pressure release on myofascial trigger point of upper fiber of trapezius measuring of pain pressure threshold and functional disability of neck. Accordingly, the current study was conducted to compare the effect of spray and stretch technique versus progressive pressure release on treatment of myofascial trigger points of upper fiber of trapezius

\section{MATERIALS AND METHODS}

The current study was conducted in the Faculty of Physical Therapy, Cairo University, in the period from November 2016 to January 2017 to compare the effect of spray and stretch technique versus progressive pressure release technique on treatment of myofascial trigger points of upper fiber of trapezius

Design of the Study: A pretest-posttest randomized controlled experimental design was used to compare the effect of spray and stretch technique versus progressive pressure release technique on myofascial trigger points of upper fiber of trapezius. As shown in the diagram of study.

Fig. 1: Diagram of the study Design

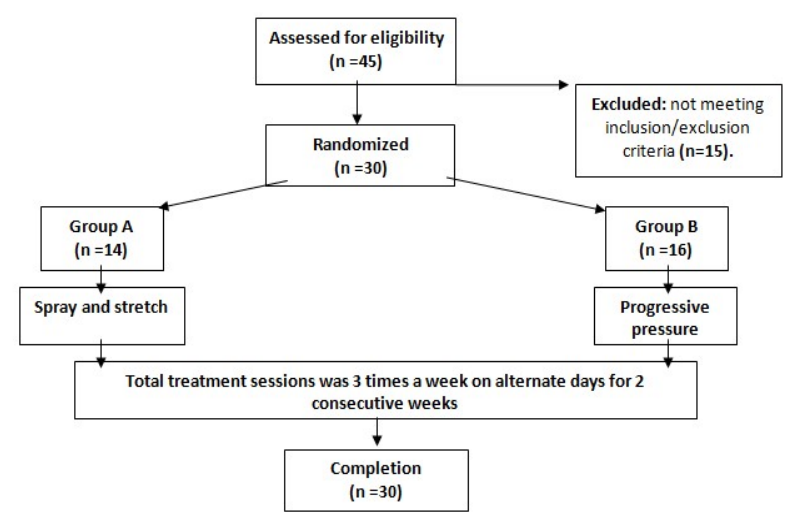

Subjects: A sample of thirty patients with active trigger point of upper fiber of trapezius with two points Trp1(mid portion of anterior of upper trapezius) and Trp2 (located caudle and slightly lateral Trp1) was assigned randomly using a random sequence generator to one of the two study groups. Subjects were recruited using publically distributed posters, online social media, and by verbal invitation. Subjects participated in the current study after the approval of ethical committee of faculty of physical therapy, Cairo University with number P.T.REC/012/001511 and all subjects provided written informed consent. Subjects were included if their age ranged from 20-35years. ${ }^{[3]}$, and painful limitation of neck lateral flexion range to opposite side of affected muscle and if they had no cervical or shoulder surgery, no fibromyalgia syndrome and no cervical radiculopathy.

\section{Instrumentation}

Pressure Algometer(PA): JTECH medical algometer made in United states of American with number443142. Pressure algometer is a device that assesses and quantifies pain pressure threshold (PPT). Quantifying PPT is an integral part and pressure algometer has been proven to be a useful instrument [16]. An algometer registers the force applied to a tissue in terms of kilograms per square centimeters. The recorded value is the amount of force which reproduces pain [17].

Neck disability index: The Neck Disability Index (NDI) is an outcome tool of ten descriptions 
which assess an individual's daily activities pain and concentrations in regards to their functional status. Each question carries six responses on a scale of 0-5 [18]. The maximum possible score is 50 . Disability is calculated using the NDI raw score as no disability (0-4), mild (5-14), moderate (15-24), sever (25-34) and complete (<34). The Neck Disability Index (IND) is the most widely used instrument in neck pain [19].

Procedures: The current study consists of three stages: Pretest measurements, Intervention period, Posttest measurements:

\section{Pretest measurements:}

Pain threshold measurement: Patient was positioned comfortably and the painful sites were identified. The site was palpated to determine the presence of myofascial trigger points in upper trapezius. A trigger point is palpated as a tender spot on taut band of muscles which produces comparable sign and jump sign. The patient is positioned accordingly and a dial type pressure algometer is placed on the site and a constant vertical pressure was applied to the site. The subject is instructed to express pain by raising their hands when only slight pain was felt, until then the pressure is increased at a constant rate. The procedure was repeated for three times and take mean difference.

Individuals daily activities pain: The individuals daily activities pain assess by Arabic version of NDI. This questionnaire was provided to the patient and is asked to answer for the same. For the patients with language barrier the examiner explained the questions and the responses to patients.

Intervention: Group (A) - spray and stretch Technique Group ( $n=14)$

The subjects were placed in a relaxed position on their homolateral hand for lying down the distal end of examined muscle (upper fiber of trapezius). At first, 3 to 5 parallel sweeps of ethyl chloride spray were connected covering the upper fiber of trapezius muscle. At that point, the muscle was placed in a maximal yet decent extend and protracted until the physical therapist felt the muscle tension hindrance. This method was rehashed 2 or 3 times [9].

Group(B) - progressive pressure release Technique
Group ( $n=16)$ Progressive pressure release connected in two stages, the initial step was to recognize and find the trigger focuses in the influenced upper fiber of trapezius, utilizing trigger point palpation. Trigger point felt as firm and restricted hyperirritable knobs with in gut of the muscle [20]. The second step was applying pressure release ranging from eight to twelve second for each pressure, then it was increased gradually for maximum of twenty seconds [10]. The total duration of pressure was five minutes or more until the discharge was felt by the fingers [21].

Posttest measurements: Pain threshold measurement and individual's activities pain were repeated as discussed before in pretest measurements after the intervention period to determine its effect.

The outcome measure for comparing the effect of spray and stretch technique versus progressive pressure release on treatment of myofascial triggers point

Statistical Analysis: All statistical analysis was carried out by using the statistical package for the social sciences (SPSS, version 20.0 for windows; SPSS Inc., Chicago, Illinois, USA). The normality of data distribution was tested through the Shapiro-Wilk test. Descriptive data and t-test were used for comparison of the mean age, height, weight and body mass index (BMI) between both groups. Paired and unpaired t-test was carried out to compare the two groups. For each group for the two tested variables (pain threshold and individuals daily activities pain). The alpha level of significance was adopted at 0.05 .

Sample size: The sample size estimation was based on power analysis in a pilot study with 10 subjects (mean difference 26.87 and SD 5.64). G* power 3.1 software (University of Dusseldorf, Dusseldorf, Germany) was used in the present study. With power $80 \%$ and probability 0.05 .

\section{RESULTS}

\section{Base line and demographic data:}

There were no statistically significant differences between subjects in all groups concerning age, weight, height, BMI ( $p>0.05)$ as shown in Table 1. 
Table 1: showing the data for subjects in all groups concerning age, weight, height, BMI.

\begin{tabular}{|c|c|c|c|c|}
\hline $\begin{array}{c}\text { General } \\
\text { characteristics }\end{array}$ & Age (yrs) & Weight (kg) & Height (cm) & $\begin{array}{c}\text { BMI } \\
(\mathrm{kg} / \mathrm{m} 2)\end{array}$ \\
\hline $\begin{array}{c}\text { Group A } \\
\text { Mean } \pm \text { SD }\end{array}$ & $25.13 \pm 3.8$ & $62.73 \pm 8.2$ & $163.13 \pm 6.8$ & $23 \pm 1.4$ \\
\hline $\begin{array}{c}\text { Group B } \\
\text { Mean } \pm \text { SD }\end{array}$ & $27.93 \pm 5.8$ & $63 \pm 7.3$ & $162.9 \pm 6.7$ & $23.6 \pm 1.5$ \\
\hline t-value & -1.54 & -0.094 & 0.08 & -1.156 \\
\hline P-value & 0.133 & 0.926 & 0.937 & 0.257 \\
\hline
\end{tabular}

Pre study means values within both groups:

Pain: As shown in table (2) the mean values and SD of pain in TP1 for groups ( $A$ and $B$ ) before the study were $(0.91 \pm 0.37),(0.99 \pm 0.41) \mathrm{kg} / \mathrm{cm} 2$ respectively. The mean values and SD of pain in TP2 for groups ( $A$ and $B$ ) before the study were $(0.89 \pm 0.43),(0.69 \pm 0.19) \mathrm{kg} / \mathrm{cm} 2$ respectively. There were no significant differences between two groups pre-study in pain level in TP1 and TP2, where P-values were (0.557) and (0.151) respectively.

Table 2: Pre-study mean values of subject's pain threshold for both groups.

\begin{tabular}{|c|c|c|}
\hline $\begin{array}{c}\text { Pain level } \\
\text { Pre-study }\end{array}$ & \multicolumn{2}{|c|}{ Upper trapezius } \\
\cline { 2 - 3 } & TP1 & TP2 \\
\hline $\begin{array}{c}\text { Group A Mean } \\
\pm S D\end{array}$ & $0.91 \pm 0.37$ & $0.89 \pm 0.43$ \\
\hline $\begin{array}{c}\text { Group B Mean } \\
\pm \text { SD }\end{array}$ & $0.99 \pm 0.41$ & $0.69 \pm 0.19$ \\
\hline t-value & -0.595 & 1.47 \\
\hline P-value & 0.557 & 0.151 \\
\hline
\end{tabular}

Individuals daily activities pain: As shown in table (3). The mean values and SD of Individuals daily activities pain for groups (A and $B$ ) before the study were $(18.66 \pm 5.73)$ and $(18.8 \pm 5.74)$ respectively. There was no significant difference between two groups in Individuals daily activities pain pre-study, where P-values were (0.950).

Table 3: Pre-study mean values of individual's daily activities pain for both groups.

\begin{tabular}{|c|c|}
\hline Items & $\begin{array}{c}\text { Individuals daily activities pain } \\
\text { pre-study }\end{array}$ \\
\hline $\begin{array}{c}\text { Group A } \\
\text { Mean } \pm \text { SD }\end{array}$ & $18.66 \pm 5.73$ \\
\hline $\begin{array}{c}\text { Group B } \\
\text { Mean } \pm \text { SD }\end{array}$ & $18.8 \pm 5.74$ \\
\hline t-value & -0.064 \\
\hline P-value & 0.95 \\
\hline
\end{tabular}

Post study mean values within both groups

Pain: As shown in table (4) the mean values and
SD of pain in TP1 for groups ( $A$ and $B$ ) after the study were $(1.08 \pm 0.39),(1.5 \pm 0.66) \mathrm{kg} / \mathrm{cm} 2$ respectively. The mean values and SD of pain in TP2 for groups ( $A$ and $B$ ) after the study were $(1.04 \pm 0.54),(1.36 \pm 0.2) \mathrm{kg} / \mathrm{cm} 2$ respectively. There were significant differences between two groups post-study in pain level in TP1 and TP2 in favor to group $B$, where $P$-values were $(0.046)$ and $(0.042)$ respectively.

Table 4: Post-study mean values of subjects pain threshold for both groups.

\begin{tabular}{|c|c|c|}
\hline \multirow{2}{*}{$\begin{array}{c}\text { Pain level } \\
\text { post-study }\end{array}$} & \multicolumn{2}{|c|}{ Upper trapezius } \\
\cline { 2 - 3 } & TP1 & TP2 \\
\hline $\begin{array}{c}\text { Group A } \\
\text { Mean } \pm S D\end{array}$ & $1.08 \pm 0.39$ & $1.04 \pm 0.54$ \\
\hline $\begin{array}{c}\text { Group B } \\
\text { Mean } \pm S D\end{array}$ & $1.5 \pm 0.66$ & $1.36 \pm 0.2$ \\
\hline t-value & -2.09 & -2.13 \\
\hline P-value & 0.046 & 0.042 \\
\hline
\end{tabular}

Individuals daily activities pain: As shown in table (5) the mean values and SD of individual's daily activities pain for groups ( $A$ and $B$ ) after the study were $(8.4 \pm 2.22)$ and $(14.9 \pm 5.24)$ respectively. There was significant difference between two groups in individual's daily activities pain post-study in favor to group $A$, where P-values were (0.065).

Table 5: Post-study mean values of individual's daily activities pain for both groups.

\begin{tabular}{|c|c|}
\hline Items & $\begin{array}{c}\text { Individuals activities pain } \\
\text { post-study }\end{array}$ \\
\hline $\begin{array}{c}\text { Group A } \\
\text { Mean } \pm S D\end{array}$ & $8.4 \pm 2.22$ \\
\hline $\begin{array}{c}\text { Group B } \\
\text { Mean } \pm S D\end{array}$ & $14.9 \pm 5.24$ \\
\hline t-value & -4.44 \\
\hline P-value & 0 \\
\hline
\end{tabular}

\section{Comparison of pre and post study for group}

A:

Pain:

As shown in table (6) the mean values and SD of pain in TP1 for group A pre and post-study was $(0.91 \pm 0.37)$ and $(1.09 \pm 0.39) \mathrm{kg} / \mathrm{cm} 2$ respectively. The mean values and SD of pain in TP2 for group A pre and post-study were $(0.89 \pm 0.48)$ and $(1.04 \pm 0.54) \mathrm{kg} / \mathrm{cm} 2$ respectively. There were significant differences between pre and post-study in pain level, where P-values were (0.000). 
Table 6: Pre-study post-study mean values of subjects pain threshold for group $A$.

\begin{tabular}{|c|c|c|}
\hline \multirow{2}{*}{$\begin{array}{c}\text { Pain level } \\
\text { Group A }\end{array}$} & \multicolumn{2}{|c|}{ Upper trapezius } \\
\cline { 2 - 3 } & TP1 & TP2 \\
\hline $\begin{array}{c}\text { pre-study } \\
\text { Mean } \pm S D\end{array}$ & $0.91 \pm 0.37$ & $0.89 \pm 0.48$ \\
\hline $\begin{array}{c}\text { post-study } \\
\text { Mean } \pm S D\end{array}$ & $1.09 \pm 0.39$ & $1.04 \pm 0.54$ \\
\hline t-value & -7.91 & -6.08 \\
\hline P-value & 0 & 0 \\
\hline
\end{tabular}

Individuals daily activities pain: As shown in table (7) the mean values and SD of individual's daily activities pain for group $A$ before and after the study were $(18.66 \pm 5.7)$ and $(8.4 \pm 2.22)$ respectively. There was significant difference between pre and post-study in individual's daily activities pain, where P-values were (0.000).

Table 7: Pre and post-study mean values of individual's daily activities pain in group $A$.

\begin{tabular}{|c|c|}
\hline Group A & $\begin{array}{c}\text { Individuals daily } \\
\text { activities pain }\end{array}$ \\
\hline $\begin{array}{l}\text { pre-study } \\
\text { Mean } \pm \text { SD }\end{array}$ & $18.66 \pm 5.7$ \\
\hline $\begin{array}{l}\text { post-study } \\
\text { Mean } \pm S D\end{array}$ & $8.4 \pm 2.22$ \\
\hline t-value & 10.34 \\
\hline P-value & 0 \\
\hline
\end{tabular}

Comparison of pre and post study for group B:

Pain: As shown in table (8) the mean values and SD of pain in TP1 for group B pre and post-study was $(0.99 \pm 0.41)$ and $(1.5 \pm 0.66) \mathrm{kg} / \mathrm{cm} 2$ respectively. The mean values and SD of pain in TP2 for group B pre and post-study were $(0.69 \pm 0.19)$ and $(1.36 \pm 0.2) \mathrm{kg} / \mathrm{cm} 2$ respectively. There were significant differences between pre and poststudy in pain level, where P-values were (0.000). Table 8: Pre-study post-study mean values of subject's pain threshold for group $B$.

\begin{tabular}{|c|c|c|}
\hline \multirow{2}{*}{$\begin{array}{c}\text { Pain level } \\
\text { Group B }\end{array}$} & \multicolumn{2}{|c|}{ Upper trapezius } \\
\hline & TP1 & TP2 \\
\hline $\begin{array}{l}\text { pre-study } \\
\text { Mean } \pm S D\end{array}$ & $0.99 \pm 0.41$ & $0.69 \pm 0.19$ \\
\hline $\begin{array}{l}\text { post-study } \\
\text { Mean } \pm S D\end{array}$ & $1.5 \pm 0.66$ & $1.36 \pm 0.2$ \\
\hline t-value & -7.24 & -11.96 \\
\hline P-value & 0 & 0 \\
\hline
\end{tabular}

Individuals daily activities pain: As shown in table (9) the mean values and SD of individual's daily activities pain for group B before and after the study were $(18.8 \pm 5.7)$ and $(14.93 \pm 5.24)$ respectively. There was significant difference between pre and post-study in individual's daily activities pain, where P-values were (0.000).

Table 9: Pre and post-study mean values of individual's daily activities pain in group $B$.

\begin{tabular}{|c|c|}
\hline Group B & $\begin{array}{c}\text { Individuals daily } \\
\text { activities pain }\end{array}$ \\
\hline $\begin{array}{c}\text { pre-study } \\
\text { Mean } \pm \text { SD }\end{array}$ & $18.8 \pm 5.7$ \\
\hline $\begin{array}{c}\text { post-study } \\
\text { Mean } \pm \text { SD }\end{array}$ & $14.93 \pm 5.24$ \\
\hline t-value & 11.5 \\
\hline P-value & 0 \\
\hline
\end{tabular}

\section{DISCUSSION}

In spite of the fact that myofascial trigger points (MTrp) are generally perceived wonders in clinical practice, there is still much to be explained with respect to their pathophysiology, mechanics of agony referral and treatment decision, from the start, it must be noticed that must of the early writing on trigger focuses, myofascial discomfort and fibromyalgia depended on one aggregate reports and the clinical encounters of those utilizing this type of treated [22].

Researchers have implemented a variety of techniques in an attempt to treat myofascial $t$ rigger points, techniques such as positional release, exercise therapy, different modalities of electro therapy, progressive pressure release, spray and stretch, post isometric contraction, have previously been shown to treat myofascial trigger points. However, most comparative analyses were inconclusive as which techniques work best [6,13-15].

Spray and stretch technique and progressive pressure release have been proved separately to be effective in treating myofascial trigger points in previous studies. But there is limited study on comparing these two techniques. Hence, the aim of present work is to compare the effect of spray and stretch technique versus progressive pressure release on myofascial trigger points of upper fiber trapezius

The results between the two groups showed significant increase in the mean value of pain threshold with group (B) in favor than group (A) after two weeks period. There was a significant 
decrease in the mean value of individual's daily activities with group (A) in favor than group (B) after two weeks period of treatment

All these findings revealed that spray and stretch technique group (A) was more effective in improving the functional activities and decrease the individuals daily activities pain than group (B) while progressive pressure release group (B) was more effective in increasing the pain threshold than group (A)

Firstly, the results of spray and stretch technique in the present study are in agreement with Rajarajeswaran P (2010) who investigated the effect of spray and stretch technique and post isometric relaxation in acute central trigger points of upper trapezius and found that spray and stretch technique is more effective in treatment trigger points [15].

The results of the current study may be attributed to the effect of spray on the skin that repress the autonomic initiation of spinal line level, which fundamentally impact the force of movement of trigger point system at the motor end plate [9]. The enhanced viability of stretch as disturbed nociceptors of the connection trigger focuses is additionally desensitized which will diminish the sensory irritability [9]. It has the ability to produce an effect on the central sensitization of the referred pain [22].

Secondly, the finding of progressive pressure release technique was supported by Fryer et al. (2005) who investigated the effect of manual pressure on MTrp in the upper trapezius muscle and they found that 60 seconds of pressure release produced significant immediate decrease in sensitivity of MTrp and increase pain threshold [23].

This concept was supported by Sahem Al Shawabka et al. (2013) who investigated the effect of positional release technique versus manual pressure release in patients with myofascial pain dysfunction syndrome; they found manual pressure release is more effective than positional release in increasing pain threshold [24].

The discoveries of progressive pressure release technique identified with restoration of uniform sarcomeres and decrease muscle pressure [9]. Likewise slow pressure enhances the circulatory status in the zone of the tight band along these lines switching the existent ischemia [25]. In addition, endorphin and encephalin discharge in the brain causing pain decrease [26].

Spray and stretch technique is very effective in improving the functional activities while progressive pressure release is effective in increasing pain threshold. Both two techniques are complementally to each other. Additionally, they could be used in treating myofascial pain syndromes, improving functional activities with increase pain threshold, prevention of future problems such as low back dysfunction, cervical dysfunctions and considered as part of the physical therapy rehabilitation program in the phase of return to the work for ordinary individuals.

Further research should be conducted to investigate the spray and stretch technique and progressive pressure release technique on other groups of muscles with trigger points, long term follow up to show the changes in conditions with time. Apply the two techniques in large sample size and show the difference between both genders.

Limitation: Limitation of this study involved only upper fiber of trapezius. Small sample size.

\section{CONCLUSION}

Spray and stretch technique group (A) was more effective in increasing functional activities than progressive pressure release group (B) While progressive pressure release group (B) was more effective in increasing pain threshold than group (A).

\section{ACKNOWLEDGEMENTS}

The authors express their sincere gratitude to all subjects who kindly participated in the study

\section{Conflicts of interest: None}

\section{REFERENCES}

[1]. C M Jackson and Marris S. Human Anatomy $6^{\text {th }}$ ed Philadelphia: Blackstons Son and Co.1991(3550).

[2]. Janet G Travel and David G Simons. Myofascial Pain and Dysfunction; the Trigger Point Manual. USA: Williams and Wilkins.1983.

[3]. Kraft G H, Johnson E W and Labanm M M. The Fibrosis Syndrome. Arc Physical Medical Rehabilitation 1968;49:155-162. 
[4]. Srikanth M, Srikumari V and Madhavi K. Effectiveness of Muscle Energy Technique on Pain and Cervical Range of Motion in Patients with Myofascial Pain in Upper Trapezius. International Journal of Physiotherapy.2015;2(1):333-340.

[5]. David G Simons and Dommerholt D. Myofascial Trigger Points and Myofascial Pain Syndrome: A critical Review of Recent Literature. The Journal of Manual and Manipulative Therapy. 2006;14:124176.

[6]. Aitor M, Angel L, Francisco G and Almudena L. effect of spray and stretch on post needling soreness and sensitivity after dry needling of latent myofascial trigger points. Archives of physical medicine and rehabilitation. 2014;95:1925-1932.

[7]. Sola A E, Rodenberger M L and Getty B B. incidence of hypersensitive areas in posterior shoulder muscles. Am. J Phs. Med. 1995;34:585-590.

[8]. Janet G Travel and David G Simons. Myofascial Pain and Dysfunction; the Trigger Point Manual.1983. 3, 5, 6,13,66,71,86,88,89 and 90.

[9]. Janet G Travel and David G Simons. Myofascial Pain and Dysfunction; the Trigger Point Manual vol : Upper Half of Body $2^{\text {nd }}$ ed. Baltimore, Williams and Wilkins.1994;131-156.

[10]. Manheim C J. The Myofscial Release Manual $3^{\text {rd }}$ ed. Grove Road Thorofare. 2001;20-53:108-130.

[11]. Barnes J M. the basic science of myofascial release. Journal of body work and movement therapies. 1999;1(4):231-238.

[12]. Baldry P E and Thompson J W. Acupuncture Trigger Points and Musculoskeletal Pain. Elsevier, Churchill and Living Stone. 2005;73-100, 222, 251 and 273.

[13]. Pragnya R, Karthika H and Antony P. Effectiveness of Ischemia Compression on Trapezius Myofascial Trigger Point in Neck Pain. International of Physical Therapy. 2016;3(2):186-192.

[14]. Dimitrios K and Kanstantine R. Effect of Topical Aerosol Skin Refrigerant (Spray and Stretch Technique) on Passive and Active Stretching. Journal of Body Work and Movement therapies.2007

[15]. Rajarajeswaran P. Effects of Spray and Stretch Technique and Post Isometric Relaxation Technique in Acute Trigger Point of Upper Trapezius. Indian Journal of Physiotherapy and Occupational Therapy. 2010;4(4):121-124.
[16]. Fabio Antonaci. Pressure Algometry in Healthy Subjects: Inter-examiner Variability. Scand J Rehabilitation Medicine. 1998;30(1):3-8.

[17]. Ethnel L and Aurie Downes. Reliability of Clinical Pressure Pain Algometric Measurement Obtained on Consecutive Days. Phys. Therapy. 1998;78(2):160169.

[18]. Howard Vernon. The neck disability index: state of the art. 1991-2008. Journal manipulative physical therapy. 2008;31(7):491-502.

[19]. Eda Tonga and Charles Philip. Cross -Cultural Adaptation, Reliability and Validity of The Turkish Version of Spine Functional Index. Health Qual Life Outcome. 2015;27:13-30.

[20]. Saxem M A. Myofascial Pain Syndrome: Characteristics, Diagnosis and Treatment. J. Ind. Dent. Assos. 1998;77(3):9-12

[21]. Andrade C K and Clifford H P. Outcome Based Massage. Philadelphia .Lippincott. Williams and Wilkins. 2001;244-260

[22]. Hou C R, Tsai L S and Hong C Z. Immediate Effect of Various Physical Therapeutic Modalities on Cervical Myofascial Pain and Trigger Point Sensitivity. Arch phys. Med. Rehab. 2002;83:1406-14014

[23]. Fryer $G$ and Hodgson L. The Effect of Manual Pressure Release on Myofascial Trigger Points in the Upper Trapezius Muscle. J. Body Work Movement. 2005;9:255-284.

[24]. Sahem M, Magdolin M and Alaa B. Positional Release Technique Versus Manual Release on The Upper Trapezius Muscle in Patients with Myofascial Pain Dysfunction Syndrome Bull. Fac. Ph. Therapy.2013;18(1):55-60.

[25]. Lillian A, Bassem El Nahass and Aly M. Myofascial trigger point's pressure release versus exercises therapy in the treatment of chronic cervical myofascial pain dysfunction syndrome. Bull. Fac. Ph. Therapy. 2010;15(1):83-92.

[26]. Chaitow D L, Delany J W and Naghn R Y. Clinical Application of Neuromuscular Techniques. The Upper Body .2000;1:69-81.

How to cite this article:

Doaa Ibrahim Amin. SPRAY STRETCH TECHNIQUE VERSUS PROGRESSIVE PRESSURE RELEASE ON TRATMENT OF MYOFACIAL PAIN TRIGGER POINT: RANDOMIZED CONTROLLED TRIAL. Int J Physiother Res 2017;5(3):21012107. DOI: $10.16965 /$ ijpr.2017.151 